\title{
Voz y verso en la poesía de Lorna Crozier
}

\author{
Carmen Leñero
}

Este ensayo es una semblanza de la poeta canadiense Lorna Crozier (Saskatchewan 1948) y una descripción de los que son, en mi opinión, sus procedimientos poéticos más significativos. El análisis cuyas conclusiones presento aquí se basa primordialmente en la labor de traducción que realicé de 60 de sus poemas, y tiene como fuentes principales los textos mismos de la autora así como una serie de conversaciones personales que mantuve con ella a propósito de su trayectoria literaria y su concepción estética.

Palabras Clave: poesía canadiense, Lorna Crozier, traducción literaria.

This essay is a biographical sketch of the Canadian poet Lorna Crozier (Saskatchewan 1948) and a description of which are, in my opinion, her more significant poetical procedures. The analysis, which conclusions I present here, is based primarily on the translation labor I carried out of 60 of her poems. It has as main sources the very texts of the author as well as a series of personal conversations I had with her about her literary career and her aesthetics conceptions. 



\author{
Carmen Leñero \\ Instituto de Investigaciones Filológicas, UNAM
}

\title{
Voz y verso en la poesía de Lorna Crozier
}

Este ensayo es una semblanza de la poeta canadiense Lorna Crozier y una descripción de los que son, en mi opinión, sus procedimientos poéticos más significativos. Dado que no existen aún estudios académicos sobre esta autora viva —-más allá de algunas reseñas y entrevistas aparecidas en prensa, o del sugestivo prólogo de Catherine Hunter a su antología Before the First Word, The Poetry of Lorna Crozier- ${ }^{1}$ el análisis cuyas conclusiones presento aquí se basa primordialmente en la labor de traducción que realicé de 60 de sus poemas (traducción que nunca antes se había realizado al español $)^{2}$ y, por supuesto, en el entusiasmo y admiración que la lectura de estos textos me provocó.

Así pues, esta primera aproximación crítica, ${ }^{3}$ que no pretende teorizar sobre una obra que se halla todavía en proceso de

\footnotetext{
${ }^{1}$ Antología publicada en la colección Laurier Poetry Series de la Wilfrid Laurier University Press.

${ }^{2}$ La antología resultante será publicada en breve por Trilce Ediciones (México) bajo el título: La perspectiva del gato, donde reúno una selección de poemas extraídos de sus dieciséis poemarios en inglés, los cuales han sido publicados, casi todos, por la editorial canadiense McClelland \& Stewart.

${ }^{3}$ Cabe señalar que el prólogo de Catherine Hunter, así como muchas de las reseñas aparecidas en la prensa (cfr. infra nota 4), a propósito de los diversos libros escritos por Lorna Crozier, tienden a poner el acento en el carácter femenino y feminista de su poesía. Un ejemplo es la nota de la periodista Barbara Carey, publicada
} 
realización, tiene como fuentes principales los poemas mismos de Lorna Crozier y el análisis que hice de sus recursos poéticos, así como la serie de conversaciones que mantuve con la autora durante los dos últimos años, a propósito de su trayectoria, su concepción estética y las estrategias de su trabajo creativo.

Lorna Crozier nació en Canadá en 1948, en la provincia de Saskatchewan, región de amplísimas praderas, salpicadas de granjas, en una de las cuales creció. Es, de hecho, una de las más importantes poetas canadienses hoy en día; ha escrito más de quince libros de poemas y ha ganado los premios de poesía más significativos de su país, incluido el Governor General's Literary Award y The Canadian Authors Association Award. Su poesía resulta particularmente brillante, lúcida y entrañable. Utiliza un lenguaje sencillo, directo, y metáforas cuya aparente naturalidad entrevera la inteligencia, la emotividad y el humor de modo exquisito, con una musicalidad propia y delicada. Esto la ha convertido en una de las escritoras más leídas y más amadas en Canadá, y lo será también para cualquier lector que entre en contacto con sus poemas, aunque sea hablante de un idioma distinto y viva en un contexto muy diferente al de esta autora.

Muchos comentaristas han explicado la poesía de Lorna Crozier asociándola con las extensas praderas canadienses, paisaje natural de su infancia y juventud. ${ }^{4}$ En la pradera canadiense,

en el Toronto Star: "Crosier's fans have to come to expect graceful clarity, sly humor, a strong affinity for the animal world and a subversive feminist tilt to the mirror she hold up to human affairs". [Los fans de Crozier están habituados a esperar de ella una claridad elegante, un humor sagaz, una fuerte afinidad con el mundo animal, y un feminismo subversivo puesto frente al espejo de los asuntos humanos que ella muestra]. Mi interpretación intentó apartarse de esta perspectiva de género, a fin de enfatizar otros aspectos de mayor relevancia, a mi entender, para la valoración de su propuesta estética y de su concepción del mundo y del lenguaje.

${ }^{4}$ Me refiero a periodistas y autores como: Doris Hillis (en su artículo: "The Real Truth, The Poetic Truth; An Interview with Lorna Crozier"; Deborah Bowen (en su artículo, "Phoenix From the Ashes: Lorna Crozier and Margaret Avison in Contemporary Mourning"); Susan Gingell (en "Let us Revise Mythologies: the Poetry of Lorna 
con sus amplios sembradíos de trigo estival, sus árboles chaparros, el panorama inconmensurable, las enormes extensiones de nieve durante el invierno, se experimenta un sentimiento de intemperie y a la vez de inminencia constante, que está presente también en buena parte de sus poemas. En medio de la pradera, los ojos y los oídos se mantienen bien abiertos para descubrir cualquier criatura o fenómeno natural que se aparezca, si bien apenas rozando la línea del horizonte — un trueno, un pequeño topo, una figura humana que se perfila a lo lejos; se ve venir una tormenta con mucha anticipación y se descubre el movimiento de la criatura más escurridiza- - Se trata de un espacio siempre listo para revelar su significado en un guiño, un chasquido. La pradera representa, pues, una entrañable inmensidad donde lo nimio se hace altamente visible y audible.

Un elemento omnipresente en la pradera es el viento y las voces que viajan en el viento, por debajo y por encima de él: "Me gustaría dibujar ese paisaje ondulante e ininterrumpido en el poema", dijo Lorna Crozier en una de las entrevistas que le hice. En alguna ocasión me mencionó también el deseo de que "sus poemas mantuvieran ventanas abiertas" para que el viento soplara a través de ellos.

Recordaba Crozier que una cantante canadiense amiga suya, k. d. lang (sic), ${ }^{5}$ nacida también en las regiones de Saskatchewan,

Crozier"); o Clarisse Foster (en su nota aparecida en The Globe and Mail), quien, por ejemplo, señala: "It is not difficult to understand why Lorna Crozier has become [...] one of Canada's bestselling poets [...], [with] her beloved Saskatchewan prairie, animals, love and coming to terms with a difficult childhood [...]. This is a poetry Canadians love to read because, in her most personal work, Crozier allows readers to see themselves directly reflected in her weather, her animals, her family, and in the pride in the land from which she comes". [No es difícil entender por qué Crozier se ha convertido en una de las poetas canadienses que más venden [...], [con] su amada pradera de Saskatchewan, sus animales, su amor y su reconciliación con una infancia difícil [...]. La suya es una poesía que los canadienses leen con mucho gusto, pues en sus textos más personales Crozier permite a los lectores verse directamente reflejados en su clima, sus animales, su familia, su orgullo por la tierra de la que es originaria].

${ }^{5}$ La cantante emplea su nombre en minúsculas en homenaje al poeta e. e. cummings. 
explicó alguna vez que su propia voz fue modelada por el paisaje de la pradera y que por eso era fuerte, de vocales prolongadas, de largo aliento. La voz poética de Lorna es todo lo contrario: es conversacional, callada, sugerente y, a veces, humorísticamente chispeante.

La nieve es en sus poemas una presencia constante, nieve que se extiende sobre los campos y se adhiere al ramaje de los árboles, al alero de la ventana. La nieve acompaña y limpia; suele ser telón de fondo, personaje, sustancia que se transforma, membrana, lente, manto suave que tranquiliza, silenciador amable del paisaje. Su intensa facultad de reflexión ilumina las escenas de Crozier e inunda de blancura incluso los momentos más oscuros en sus poemas.

Hoy en día, y desde hace varios años, Lorna Crozier vive en Victoria, capital de la provincia de la Columbia Británica; su entorno ya no son las praderas, sino los intrincados bosques de lluvia, los sembradíos de tulipanes y de calabazas, las frías costas de la isla de Vancouver. Toda isla, por su aislamiento en medio de las aguas, adquiere carácter de mundo autónomo, y la de Vancouver, en particular, con su explosión de flores y su ambiente de jardín y de retiro, recuerda el modo en que la poeta transcurre por sus poemas: merodeo en torno a una imagen central que va abriéndose a sus significados más entrañables o imprevistos, verso tras verso.

A la idea de las distintas voces del viento que atraviesa las praderas se vincula la forma de memoria que prefiere Lorna Crozier. El viento trae desde la lejanía los sucesos del pasado, los recuerdos de infancia, las visiones súbitas, las invenciones tempranas e incluso escenas míticas. Pero es también la inmensidad de las praderas, que la conciencia de Lorna Crozier ha convertido en una dimensión íntima, una geografía interiorizada, lo que le permite colocar en perspectiva esos recuerdos y esas visiones, poniéndolos a la suficiente distancia para que puedan 
ser observados y recuperados como experiencia del presente. Crozier no es poeta de situación, sino de viva rememoración. De ahí el carácter vibrante y conmovedor de sus poemas, tanto como esa especie de lucidez fría que en ellos se despliega.

A este doble movimiento de alejamiento y penetración se suma otro tipo de ejercicio realizado también por su memoria poética: la andanza. En muchas ocasiones Lorna Crozier compone sus poemas mientras camina por algún sendero del bosque, por la arena de una playa o por los pasillos del Departamento de Escritura Creativa en la Universidad de Victoria, donde enseña. Va memorizando cada estrofa, vuelve al principio, explora posibilidades, avanza y retorna hasta que el poema está completo en su cabeza, antes de sentarse a escribir el primer verso. Guían su caminata un ritmo y una cadencia anteriores a la materia verbal, ausente aún pero inminente. "Al empezar un poema hay cosas que sé y hay cosas que no sé - explica la autora-; me dejo guiar por los sonidos." Es pues su cantar interno, unido a su andanza, lo que propicia el advenimiento de cada metáfora: su voz callada va modelando y remodelando las escenas conforme se desplaza, y gracias a ello logra dar cauce a las que Rainer María Rilke llama "memorias de la sangre", ${ }^{6}$ flujo de emociones que atraviesa el texto poético.

Hay en este proceso de composición un trabajo artesanal, ajeno sin embargo a la elaboración retórica o al manoseo psicológico. Crozier no reinventa sus recuerdos; por el contrario, los observa desde un nuevo enfoque, "frío" y acucioso. Un trabajo interior previo, el trabajo del olvido, ha limado las imágenes que vienen espontáneas a la mente cuando algo en el entorno inmediato las provoca, quizá un sabor, un sonido, el pulso de la luz o un simple rumor. Una vez que el olvido ha pulido aquella imagen ausente del recuerdo, el despliegue "musical" proveniente del cuerpo le dará una existencia intensamente perceptible en el presente del lector.

${ }^{6}$ Blood memories, las llama Crozier en su lengua. 
Para Lorna Crozier, su destino de poeta significa no sólo haber escrito poemas durante toda su vida, sino un continuo estado de atención. Atención a lo que mira, pero sobre todo a lo que escucha detrás, dentro y alrededor de aquello que su mirada descubre. Hacer poesía implica un tipo peculiar de alerta. Vivir en tal estado de atención es lo que la poeta extraña, según dice, durante los periodos en que por alguna razón deja de escribir. Su concentración no consiste en buscar deliberadamente una metáfora para expresar lo que observa, una parábola eficaz o una sabrosa analogía - "esas cosas vendrán por sí solas", asegura—; constituye más bien un estado sosegado de escucha.

Uno de los escritores preferidos de Lorna Crozier, John Berger, afirma que "la poesía está en oír". Para ella también la escritura poética no es propiamente invención, ni siquiera traducción de una visión íntima, sino un escuchar la voz de las cosas. Las cosas son sólo lo que son, explica, y para escribir un poema sobre ellas: "las cosas mismas me tienen que hablar". No se trata, pues, de manipularlas o reconstruirlas, sino de explorar lo que las criaturas, los fenómenos y los objetos son capaces de "decir". Hay que descubrir, de manera intuitiva y devota, las metáforas que han estado siempre ahí, en el mundo; instalarse en una escucha propiciatoria que saque esas metáforas a la luz. Crozier se asombra de cómo la voz de la naturaleza, por sí sola, hace poesía.

Crucial para su quehacer poético es saber oír en especial a los animales: al conejo, al ganso, al coyote, al halcón, a la polilla, al perro, a la urraca, al gorrión, a la araña, a la tuza, al gato. A todos ellos se acerca con un amor, más que compasivo, empático. Se ve expresada ella misma en sus actitudes, en su comportamiento, en su presencia. Siente fascinación por el mis- 
terio de todo lenguaje animal, e intenta conectarse con el dolor de los animales, con sus perplejidades: "Nunca encuentras las palabras para decir el modo en que dos criaturas de distinta especie se miran", dice.

En este sentido, uno de sus poemas más estremecedores es "Miedo a las serpientes", donde el mito bíblico del Génesis, trasmutado, se trenza con un episodio de infancia y una punzante meditación del alma. En este poema evoca la asociación que se hace de la serpiente con la culpa y la violación erótica, así como el atávico temor y atracción que provoca este animal - en cuanto símbolo del mal, de la mujer, de lo prohibido- - para finalmente hallar una intensa afinidad entre ella y la criatura. Varias emociones se alternan en el transcurso de su narración poética: pánico, curiosidad, deseo, compasión, bajo una mirada distante y una voz descriptiva que sin embargo toca profundamente al lector.

\section{[...] Recuerdo}

cuando el miedo a las serpientes me dejó, desprendiéndose de mí como una vieja piel.

[mi hermano y yo]

vimos cómo Larry la clavaba al poste del teléfono.

Ella se retorció entre ambos clavos, gemelos iridiscentes, incapaz de arrastrarse hacia afuera del dolor, su boca abierta, la lengua roja paladeando su propio espanto; la amé entonces, a esa serpiente. Los chicos ahí parados con sus manos idiotas colgando de las muñecas, y aquella boca verde $\tan$ hermosa, abriéndose en una $\mathrm{O}$ terrible y negra que nadie podía escuchar. ${ }^{7}$ 
Esta $O$ final, onomatopeya muda de la serpiente aterrorizada, desahoga el poema en medio de la oscuridad y el silencio. Pero antes, ese mismo sonido vocálico ha venido serpenteando verso tras verso, primero para expresar el miedo de una niña que está siendo perseguida por un puñado de chicos crueles - que pretenden aventarle la serpiente encima-, y después para dar voz a un simple animal indefenso, sometido a tormento. Esa $O$ negra y abismal, como el interior de un pozo, sólo puede ser escuchada por aquella chiquilla que la poeta recuerda haber sido. Es una especie de grito controlado, cifra donde se funden el terror animal y el terror humano, particularmente el de una mujer-niña, que pasa a ser doblemente víctima junto con la serpiente, y que doblemente se rescata desde la perspectiva de la ternura y la compasión. El símbolo del mal, la culpa y el pecado se ha transfigurado en motivo de iluminación, a partir de la negrura y el vacío que "le hablan al oído" a la poeta. Esa $O$ actúa también como una especie de ojo que la espía desde una dimensión prehumana, el ojo de un Dios extraño, agazapado, que alcanza a la niña ahí, entre los matorrales tras los que se escondió, y desde donde ella lo espía también a él. Así pues, la vocal muda en la boca abierta de la serpiente, cuya extraña resonancia zigzaguea animalmente de línea en línea (formando el cauce fónico del poema tanto como su cadena meditativa), denota una ausencia, un vacío igual al del filósofo oriental que lo concibe como principio propiciatorio de toda forma ulterior: "El vacío es la forma y la forma es el vacío", dice el Tao te King.

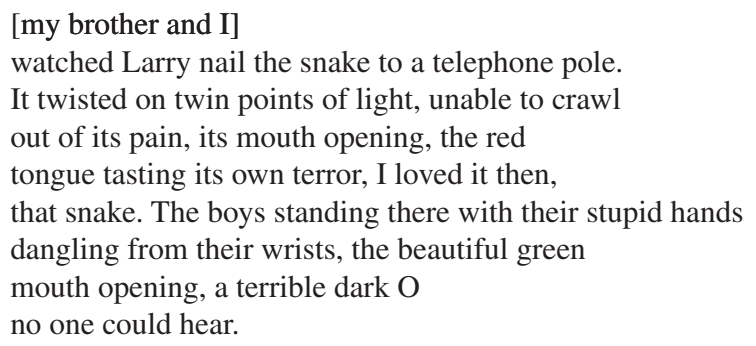

("Fear of Snakes", Angels of Flesh, Angels of Silence, 57).

Todas las traducciones que aparecen en este artículo son mías (cfr. supra nota 2). 
Lorna Crozier se empeña en escuchar incluso la voz del vacío, como si éste fuera también una criatura viva, capaz de nacer, crecer, reproducirse y decir su vaciedad en un alarido silencioso o en una fulminante onomatopeya: “Zzzp”. Así sucede con el "cero" en el "Poema sobre nada":

Le pregunto a mi amigo,

el retórico que estudia matemáticas, ¿qué significa el cero en términos simples?

Contesta Zzzp. ${ }^{8}$

Concentrada en esta cifra y su misterio, la poeta despliega su fascinación por aquello que falta en el paisaje o en el episodio que rememora, aquello que no es visible.

El cero se inmiscuye

entre uno y uno

y todo se modifica.

Se cuela en el alfabeto.

Es vocal en la lengua muda,

es pupila en el ojo del ciego,

es la imagen

que retiene

de una cara, en la punta de sus dedos. ${ }^{9}$

$8 \quad$ I ask my friend

the rhetorician who studies mathematics

What does zero mean and keep it simple.

He says Zip.

("Poem about Nothing", The Garden Going On Without Us, 15).

Zero worms its way

between one and one

and changes everything. 
Nuevamente lo ausente se convierte en espacio de intenso deseo, de provocación: la nada de donde surgen escenas y mundos. Quizá por eso el poema termina con el verso

En el principio, Dios creó el cero. ${ }^{10}$

Lo que adviene gracias al oído atento y al ejercicio de la voz poética es, pues, aquello que no está presente: un episodio de infancia, un fragmento de música atesorado en la memoria y capaz de sufrir innumerables variaciones, o bien, momentos "olvidados" e inadvertidos de la rutina. Ello ocurre de manera muy clara en un poema como "Las variaciones Goldberg":

Nunca me sentí tan desconectada de todo. Luz y su ausencia.

Lluvia. El gato en el alféizar cazando moscas.

Glenn Gould tocando Las variaciones Goldberg por última vez.

Las infinitas variaciones de ti, haciendo el café, encargando semillas para el jardín, invitándome a subir para el amor $[\ldots]^{11}$

It slips inside the alphabet.

It is the vowel on a mute tongue,

the pupil in a blind man's eye,

the image

on the face

he holds on his fingertips.

("Poem about Nothing", The Garden Going On Without Us, 17).

10 In the beginning God made zero.

("Poem about Nothing", The Garden Going On Without Us).

11 Never have I felt so unconnected to everything. Light and its absence.

Rain. The cat on the windowsill catching flies.

Glenn Gould playing the Goldberg Variations

his last time. 
Si la poesía radica en oír, sobre todo lo que está ausente, Crozier tuvo razón cuando dijo, mientras me explicaba alguna de sus más enigmáticas líneas: "el poeta es como un fotógrafo ciego, pues avanza en un espacio que desconoce".

\section{$* * *$}

Puesto que Lorna Crozier escribe en inglés, en sus poemas asoma toda la tradición de la poesía inglesa; en particular, ella menciona su directa filiación con Shakespeare - por su constante variación de metros-, con Yeats, Keats y Tennyson. También resuenan en su voz acentos de la música country - especialmente la de Hank Williams, con su simplicidad hasta la médula del hueso y esa sencillez de un lenguaje que puede entender cualquiera- - La poeta sabe oír íntimamente las voces que respiran en otros poemas y textos: la voz metafísica de Plath, por ejemplo, la voz iracunda de Atwood o la voz sin adornos de William Gass. Se nutre con todas ellas para expresarse, sin embargo, a su manera muy particular.

Más que hablar de intertextualidad, hablo de una intensa "intervocalidad" en su escritura. Alusiones bíblicas, dichos de sabiduría oriental, versos antiguos, trozos de leyendas, refranes populares, estribillos de canciones son recuperados por Lorna Crozier menos como textos que como manifestaciones de una voz que su poema acoge y difracta en los variados tonos de su propia tesitura. Conducida por la expansión musical de una cita, su voz acaba trastornando el sentido del mundo al que la cita alude. Y de esta manera dialoga con ella en un terreno nuevo y personal.

The endless variations of you, making coffee, ordering seeds for the garden, calling me upstairs to love [...]

("The Goldberg Variations", Angels of Flesh, Angels of Silence). 
Así sucede con especial gracia en los ghazals que aparecen en su libro Bones in Their Wings. ${ }^{12}$ El ghazal es una forma poética originaria de Persia, ampliamente explorada por la literatura $\operatorname{suf}^{13}{ }^{13}$ y desarrollada con destreza por importantes poetas modernos de lengua inglesa. ${ }^{14} \mathrm{Se}$ compone de una serie de dísticos (de 5 a 12) que se engarzan sólo por el ritmo, todos ellos independientes en cuanto a su significado, pero capaces de entretejerse unos con otros de manera enigmática en la mente del lector, formando una especie de canto tentativo. No hay, pues, una obvia relación entre los dísticos, ni una cronología, sino sólo una armonía secreta que no tiene que ver con ningún tipo de consecución lógica o de solución narrativa al final del texto. El ghazal pide del lector una enorme confianza y flexibilidad para entregarse al juego de asociaciones espontáneas que el poeta propone. Su peculiar composición lo convierte en una auténtica danza de imágenes, dichos, ideas y juegos musicales, que sólo se aprecian en la lengua en el que fue originalmente escrito:

If someone is not as he should be, he has misfortune. ${ }^{15}$

To be, do be, doo. Hamlet scatting

"Your feet's too big" (sic). ${ }^{16}$

${ }^{12}$ De este libro, el reseñista Joseph Blake comentó: "It's a brilliant, inspired, little book brimming with poetic fireworks" [Se trata de un pequeño libro, brillante, inspirado, que rebosa poéticos fuegos artificiales] (Victoria Times Columnist, 6).

${ }^{13}$ En su ensayo "Dreaming the Ghazal into Being" (incluido en su poemario Bones in Their Wings, 62 y ss.), Lorna Crozier se refiere a los poetas de esa antigua tradición cuya voz resuena mayormente, o incluso aparece citada, en sus propios poemas: se trata de Rumi, Ghalib y Háfiz.

${ }^{14}$ Poetas como Adrienne Rich, Jim Harrison, John Thompson, Phyllis Webb y Patrick Lane han escrito ghazals de notable delicadeza y poder, afirma Lorna Crozier ("Dreaming the Ghazal into Being", Bones in Their Wings, 64).

${ }^{15}$ Cfr. Hexagrama "El aumento", en I Ching o Libro de las Mutaciones chino: "Si alguien no es veraz, tendrá desgracia" (246).

${ }^{16}$ Estos dísticos de Lorna Crozier son difícilmente traducibles debido al juego musical que parodia el famoso "To be or not to be" del monólogo shakesperiano, así como a la frase musical que le sigue, proveniente de una canción de Fats Waller. 
El nombre en árabe de esta forma poética, originalmente cantada, es gazel (gacela), quizá porque su espontaneidad emotiva, su balbuceo y deriva conceptual remiten al lamento de una gacela herida antes de morir. Las "reminiscencias verbales" con las que se construye el ghazal quedan sometidas a la dinámica del azar, el juego, el canto y el baile, un baile de apariciones movedizas en la mente del lector. Dístico tras dístico, el poeta va generando una pieza vibrante con gran poder evocador, tanto como lo sería un koan, un haikú o un proverbio de iluminación. La vocación aforística y la libertad cantarina de Crozier, libertad de alternar una respiración meditativa y una articulación juguetona, hacen de sus ghazals delicias de una inteligencia diestra en combinar la ironía y la delicadeza.

El control que ejerce la poeta sobre sus imágenes, libres asociaciones y breves relatos proviene ciertamente de su sentido musical de la composición, tanto en los ghazals como en el resto de las formas poéticas que adopta. De ahí que la pequeña sorpresa que genera cada uno de sus versos ocurra con toda naturalidad. De hecho, su preocupación primordial como escritora es la de ser musical y coloquial a un tiempo, de modo que en sus poemas cante íntimamente al oído del lector, como si se tratara de una conversación fluida y provocativa a la vez. Por eso emplea un vocabulario generalmente simple sin adorno ni alevosía, metáforas directas, pero también rimas escondidas, rupturas heterodoxas de los versos, diálogos, cambios de sintaxis y de dicción que aproximan el lenguaje poético ora a las espontáneas cadencias de la prosa, ora a las atávicas fórmulas del canto.

Si alguien no es como debiera habrá desgracia.

Ser, no ser, lari-lara. Hamlet tararea

"Tus pies son enormes".

(Bones in Their Wings, 8). 
Esencialmente lo que hace Lorna Crozier es someter su concentrada atención en la imagen a un flujo musical guiado por sonidos vocálicos que se repiten y despliegan, más que a la rima propiamente dicha. "English is famously rhyme-poor, many words having only one mate and several having none", ${ }^{17}$ explica. ${ }^{18}$ Además, en inglés se tiende a escuchar más la caída o elevación de los sonidos acentuados e inacentuados que el número de sílabas. Son, pues, los sonidos vocálicos y algunos consonánticos los que generan en los versos de Crozier la sensación de rimas internas y de resonancias musicales, no como un lujo retórico sino como sustancia misma que da vida y verdad vivencial al poema. ${ }^{19}$

De la sonoridad de las vocales depende no sólo el color de la emoción que la poeta va trabajando sino la elección de un adjetivo, un sustantivo, un verbo. El pensamiento, así, encuentra su vertiente y empieza a transcurrir en determinada dirección. Primero por afinidad sonora, y luego por cautelosa asociación, la poeta logra movilizar el material psíquico más oculto.

${ }^{17}$ Se sabe que el inglés es pobre en rimas, dado que muchas palabras cuentan sólo con una pareja consonante, o incluso con ninguna. En español, en cambio, es difícil escribir sin rimas, quizá debido a la regularidad de las conjugaciones verbales y al sistema de sufijos que abundan en la conformación de nuestros vocablos.

18 "Dreaming the Ghazal into Being", Bones in Their Wings, 30.

${ }^{19}$ La escritura de Crozier presenta, además de las resonancias vocálicas de fuerte efecto significante, patrones estructurales de composición (paralelismos, simetrías, contrapuntos por cambio de escenario, voces o entonación) que realmente asemejan cada uno de sus poemas a una pieza musical. Así, por ejemplo, suele suceder que el carácter métrico de los versos iniciales se reencuentre a mitad del poema, después de haber sufrido variaciones, suspensos o circunvoluciones; que distintas estrofas se espejeen, mostrando posibilidades distintas de una misma cadencia; que los espacios en blanco, pausas en la melodía verbal de las líneas, abran compases de resonancia armónica en la mente del lector: ecos de escucha interna y meditación; y que la parte final de los poemas a menudo constituya una especie de coda, donde el tema central se ha desdibujado para ofrecer una sorprendente proposición nueva, iluminadora o tranquilizante, tanto en el concepto como en la forma. Cuando Lorna Crozier da una lectura de poesía, en realidad no lee sino recita su poesía de memoria. Sus inflexiones revelan al oyente las peculiaridades "performativas" de su voz poética, y le descubren a un tiempo el corazón acústico y emocional de los poemas. 
El surgimiento y recurrencia de un sonido (como aquella $O$ en la boca abierta de la serpiente) generan el cauce del poema. ${ }^{20}$ Sonido e imagen en consonancia van configurando un instante de experiencia que salta de escenarios ubicados en tiempos distintos, que oscila entre la contemplación y el relato: un deambular que lleva no hacia el final sino hacia el centro íntimo del poema. Para Crozier, la escritura consiste en dar vueltas en torno a un objeto, una imagen, un recuerdo, de la misma manera en que lo hace, por ejemplo, un gato ${ }^{21}$ — criatura que explora así los rastros, los sabores, las cosas que encuentra en su camino- - Y esa indagación constituye el cuerpo móvil de lo que la poeta escribe. La suya es una música del cuerpo, atemperada en los huesos, encarnada en desplazamientos concretos, latidos, caricias, rasguños; una música corporal que, trasladada a la escritura, da forma al río de emociones que bulle entre las líneas.

Podríamos decir que "la música" que despliega una determinada voz poética se expresa en el uso de ciertas palabras y no otras, en la recurrencia a ciertos acomodos sintácticos, en la adopción de ciertos tonos que en cada escritor adquieren un

${ }^{20}$ Tanto como sucede con el vocablo nevermore en el poema "The Raven", de Edgar Allan Poe.

${ }^{21}$ Según me comentaba en una de nuestras entrevistas, Lorna Crozier posee un gato, y a menudo lo observa, aprende de él, conjetura qué impulsos lo mueven. Ama a su mascota, más aún, la admira. Una fuerte empatía la une con este felino dulce y a la vez impredecible, tan caprichoso en sus acciones y merodeos como Dios o el azar. La criatura se llama Basho: "los nombres de los poetas les quedan bien a los gatos", me dijo en alguna ocasión. En efecto, las estrategias creativas de Crozier imitan de alguna manera los movimientos y actitudes de Basho, su gato: Sentirse, al menos mientras se escribe, como un pequeño animal que ignora el tiempo pues vive en el presente y sólo como presente habita los recuerdos o las premoniciones. Soñar durante horas, o bien estar alerta a lo que dicen las cosas y el entorno. Ser, mientras se compone un poema, un ser de espacio. Generar el espacio de dentro hacia fuera, mediante el desplazamiento, el roce o el gesto. Convertirse, al menos cuando se siguen las huellas de un verso, en un felino que se deja conducir por su olfato, y no se pierde. Irremediablemente independiente, sale de casa, deambula, se adueña centímetro a centímetro del exterior y lo hace formar parte de su cuerpo en acción. Es libre y puede alejarse mucho, pero siempre regresa. 
poder de evocación particular, en la alusión a cierto tipo de imágenes y el olvido de otras, en los vaivenes de la propia respiración interna del poeta, en su modo de andar por los paisajes imaginados, así como en los sitios del pensamiento en que se detiene o que abandona con premura. Si bien música y memoria son las musas tutelares de Lorna Crozier, su extrema intuición lingüística y su elegancia intelectual mantienen en equilibrio el ímpetu de ambas. Música y memoria se vierten juntas en un presente, específico y actual, y ese momento presente al que el poema "invita" es a lo que me refiero cuando hablo del "centro íntimo del poema".

De este modo, "Las variaciones Goldberg", compuestas por Bach y tocadas por Glenn Gould con sus propias variaciones, son re-escuchadas en medio de las sutiles variaciones del acontecer cotidiano y amorosamente recogidas en el canto secreto de Crozier. Ese canto en tiempo presente, seducción que atrae a la presencia lo ausente, atiende, pues, a una música que ha viajado de mano en mano, de época en época, hasta su pluma. Una pluma poseída por lo distante.

Los dedos de Gould sobre teclas de marfil.

No es Bach lo que interpreta

desde la tumba, corazón en pausa.

Tan libre de gravedad la mente asciende

como una semilla alada, apenas

contenida en una cáscara ligera

[...]

¿Es esto el éxtasis,

esta extraña sensación de lejanía? ${ }^{22}$ 
Podemos señalar entonces que en los poemas de Lorna Crozier la música no es la forma que adopta el contenido; es el contenido mismo, que dicta el ritmo y dirección del pensamiento durante la escritura. Ello le permite un control estético de la sustancia emocional y del flujo de imágenes, para que el texto no se convierta en mera catarsis del delirio o en simple desahogo de los recuerdos. La música del poema constituye el interregno entre la racionalidad del lenguaje y el delirio del corazón, entre el mundo natural y el mundo acústico de la lengua. La realidad se resiste a ser dicha por el lenguaje, lo sabemos todos. De esa resistencia surge el poema, surge de ese "grito controlado" de la serpiente, vocal muda: el silencio vibrante que acecha entre los versos.

\section{$* * *$}

En la poesía de Crozier, lo insignificante se vuelve origen. Su visión, o más bien dicho su concentración en las cosas, hace que de ellas, de cualquier pequeña criatura, de un gesto incluso, brote el paisaje, el universo entero:

El gato crea el mundo

al toque de su pata, al leve rasguño del bigote,

[...]

Después de aves canoras y trepatroncos, después del tordo, el pájaro carbonero y el pinzón, el gato crea al ratón, al abejorro y a la araña, a la libélula luego, que se agita en el paladar ranurado de su boca, una palabra con alas. ${ }^{23}$

[...]

Is this ecstasy,

this strange remoteness?

("The Goldberg Variations", Angels of Flesh, Angels of Silence, 68). 
También en el poema fundacional "Apócrifo de la luz", fue la propia luz quien dijo: "Hágase dios / Y Dios fue creado". ${ }^{24}$ Luego, bajando y subiendo por la oscuridad, dio visibilidad y con ello vida a la creación.

Cayó y dio vueltas en el agua

hasta que mares y ríos no pudieran desprenderse

de su brillo. Se demoró:

en ese reloj de arena

de las peras de agosto; en el mirlo,

las heces del oso y la sangre del ternero;

en la mano del amado,

su inusitado destello.

A todas partes llegó alumbrando

lo que esperaba ser visto $[\ldots]^{25}$

\section{[...]}

After warbler and nuthatch, after thrush, chickadee, and finch, the cat makes mouse, bumblebee, and spider, then the dragonfly that beats on the rilled roof of his mouth, a word with wings.

("Lesson in Perspective", Apocrypha of Light, 7).

${ }^{24}$ La poeta trastoca el pasaje inicial del Génesis: "Versículo 1. En el principio crió (sic) Dios el cielo y la tierra. V. 2. La tierra empero estaba informe y vacía, y las tinieblas cubrían la superficie del abismo: y el espíritu de Dios se movía sobre las aguas. V. 3. Dijo pues Dios: Sea hecha la luz, Y la luz quedó hecha. V. 4. Y vio Dios que la luz era buena; y dividió la luz de las tinieblas" (La Sagrada Biblia, 2). Las cursivas son mías.

25 It splashed and rolled in water

till rivers and seas could not be parted

from its gleam. It lingered:

on the hourglass

of August pears; on blackbird,

bear scat, calves' blood;

on the hand of the beloved,

its unlikely flare. 
Algo similar sucede en el poema "Inventando al halcón", cuyo grito primigenio y simple existencia van generando la naturaleza toda; sus planeos por el aire provocan la aparición del cielo, y su cacería misma crea a las pequeñas presas de que se alimenta. Nuevamente, como en otros de sus textos, Crozier impone una lógica invertida: en vez de ir del paisaje a la cosa, va de la cosa - el animal, la luz, el grito, la mirada - a la aparición del mundo. La criatura es la causa y no el objeto de la Creación. "Inventando al halcón" alude también a un pasaje bíblico, la Anunciación. ${ }^{26}$ Pero en el poema se trastocan las significaciones originales y se propone una nueva interpretación del mito: es el chillido de un halcón —y no el Verbo- el que concibe en el vientre de una mujer que vive en las praderas canadienses - y no de la Virgen María — la encarnación, no de Dios, sino del planeta. La poeta, quien ha acogido este gemido animal dentro de sí, se siente obligada a asegurar la continua regeneración del universo mediante su palabra poética, propiciando con su canto - como hacían tradicionalmente los indios de Norteamérica- la renovación diaria de la naturaleza; salvando a las especies en peligro de extinción y recobrando la amplitud de los cielos gracias al simple vuelo de un ave.
Ya tenía su voz al menos, un grito surgido desde el vientre, resonando en el cuenco invertido y oscuro de su cráneo.

Ella inventó sus alas, pluma tras pluma, la roja suavidad de su cabeza,

\footnotetext{
It went everywhere, glossed all that waited to be seen $[\ldots]$

("Apocrypha of Light", Apocrypha of Light 3).

${ }^{26}$ Evangelio de Lucas (1: 26-38), en La Sagrada Biblia, t. IV, 81.
} 
sus ojos como joyas refulgentes

en el trance entre dormir y despertar. ${ }^{27}$

Partiendo de lo que ocurre en su interior más íntimo, la poeta reconstruye el exterior, y así entra en amistad con las cosas y el entorno - condición que, como dijo la filósofa María Zambrano, constituye el ser mismo del alma-. Así como la criatura viva propicia la creación, así la vocal vibrante y sus resonancias propician el adjetivo, la imagen, el sentido de un relato, la difracción de un recuerdo en el poema. El poeta crea (como cualquier otra criatura de la naturaleza), no con rasguños, graznidos y acrobacias aéreas, sino con palabras que vienen a su voz desde lo más profundo del cuerpo. Si en verdad es el canto la dinámica que guía la escritura poética, para Lorna Crozier el hecho de cantar realiza una especie de acto chamánico: permitir que la naturaleza misma se exprese en el lenguaje.

$* * *$

Sí, la musicalidad de Crozier quiere expresar a las criaturas. $\mathrm{Y}$ hay que tomar en cuenta que todo lo que se manifiesta ante su delicada percepción tiene vida y "dice" algo: no sólo los hombres y los animales, sino también las plantas, las piedras, la nieve, el viento y el paisaje. Su manera de escribir responde al anhelo de ser fiel a esta acústica de la naturaleza, a su "poesía" intrínseca, más que a una estrategia de seducción para el pensamiento o la

Already she had its voice,

the scream that rose from her belly

echoed in the dark inverted

canyon of her skull.

She built its wings, feather by feather, the russet smoothness of its head, the bead-bright eyes, in that moment between sleep and waking.

("Inventing the Hawk", del libro con el mismo título, 44). 
imaginación del lector. La autora confiesa que su ejercicio poético se inspira en la búsqueda de aquel lenguaje primordial con que los humanos, en algún tiempo mítico, podían hablar con los animales. Sólo el canto (cuerpo vibrante y palabra fundidos) es capaz de evocar ese lenguaje primordial que, de acuerdo al sueño de la poeta, permitiría la comunicación entre especies distintas, entre el agua y el sapo, entre Dios y la jirafa, entre la luz y la pantera, entre una mujer y su gato. A la caza de este lenguaje primigenio, Crozier escribe, por ejemplo, "Torre de Babel":

Y en la tierra toda una sola lengua $y$ un solo hablar. ${ }^{28}$ Venado habla con mujer mujer con zorro, sin temor ni suspicacia. Urraca conversa con rata almizclera, y jah, la hierba!, qué húmedo y elocuente coloquio verde sostiene con la llovizna. ${ }^{29}$

¿Habrá en realidad una música corporal y callada, una cadencia virtual previa al poema, previa al lenguaje mismo, de donde surgen las metáforas más puras? ¿Podrá la escritura poética "encantar" a las palabras que atraviesa para dejar salir, como dice el poeta Ramón Xirau, ${ }^{30}$ los significados fijos que ya tienen, y para que de ellas surjan pensamientos libres, felizmente extraviados mientras el canto dura?

${ }^{28}$ El comienzo de este poema remite al capítulo XI del Génesis, donde se narra la construcción de la Torre de Babel. Pero Crozier trastoca el sentido original de dicho pasaje, el de la confusión de lenguas, con el de una lengua originaria e inocente, compartida por todas las criaturas.

$29 \quad$ And the whole earth is of one language

and one speech. Deer talks to woman

and woman to fox, no mistrust or fear.

Magpie chats with muskrat, and oh, the grass! How wet and eloquent its green jive with the rain.

("Tower of Babel”, Apocrypha of Light).

${ }^{30} \mathrm{Cfr}$. Sentido de la presencia, 63-87. 
La poesía de Lorna Crozier apuesta por esta posibilidad soñada de aproximarse a la musicalidad intrínseca de las criaturas, música anterior al lenguaje, y se presenta ante nosotros como un canto que apela a nuestro más recóndito oído. 


\section{REFERENCIAS}

Bowen, Deborah, "Phoenix from the Ashes: Lorna Crozier and Margaret Avison in Contemporary Mourning", Canadian Poetry: Studies, Documents, Reviews, 40, 1997, 46-57.

Burke, Anne, "Lorna Crozier: the Writing is All", Cross-Canada Writer's Quarterly, 10: 3, 1988, 5-6 y 26.

CARey, Barbara, "On Apocrypha of Light by Lorna Crozier", nota aparecida en Toronto Star 198, 2002, 10-11.

Crozier, Lorna, The Weather, Saskatoon [Canada], Coteau Books, 1983.

- The Garden Going on Without Us, Toronto, McClelland \& Stewart, 1985.

—, Angels of Flesh, Angels of Silence, Toronto, McClelland \& Stewart, 1988.

_- Inventing the Hawk, Toronto, McClelland \& Stewart, 1992.

—, Everything Arrives at the Light, Toronto, McClelland \& Stewart, 1995.

_- A Saving Grace, Toronto, McClelland \& Stewart, 1996.

_- What the Living Won't Let Go, Toronto, McClelland \& Stewart, 1999.

—, Apocrypha of Light, Toronto, McClelland \& Stewart, 2002.

_- Bones in Their Wings: Ghazals, Regina [Canada], Hagios Press, 2003.

—, Whetstone, Toronto, McClelland \& Stewart, 2005.

Foster, Clarisse, nota aparecida en The Globe and Mail, abril 20 de $2005,5$.

Gingell, Susan, "Let Us Revise Mythologies: the Poetry of Lorna Crozier", Essays on Canadian Writing, 43, 1991, 67-82.

Hillis, Doris, "The Real Truth, The Poetic Truth. An Interview with Lorna Crozier", Prairie Fire, 6: 3, 1985, 4-15.

Hunter, Catherine, prólogo a la antología Before the First Word: The Poetry of Lorna Crozier, Ontario, Wilfrid Laurier University Press, 2005, vii-xvii (Laureir Poetry Series).

I Ching. El libro de las mutaciones, Hermes Sudamericana, Buenos Aires, 1976.

La Sagrada Biblia (t. I y IV), trad. D. Félix Torres Amat (de la Vul- 
gata al español), Barcelona-México, Unión Tipográfica Editorial Hispano-Americana, 1953.

MeYer, Bruce y Brian O'Riordan, "Nothing Better Than Poetry? An Interview With Lorna Crozier", Poetry Canada Review, 10:1, 1989, 1-3.

XIRAu, Ramón, Sentido de la presencia, México, Fondo de Cultura Económica, 1997 (Tezontle). 